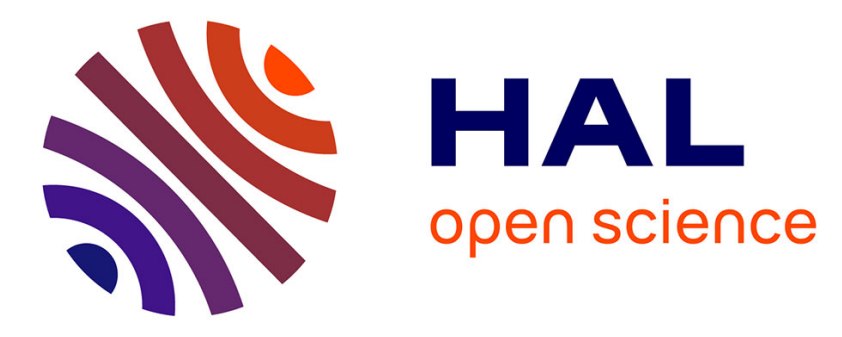

\title{
Modeling of Heat Transfer and Unsaturated Flow in Woven Fiber Reinforcements during Direct Injection-Pultrusion Process of Thermoplastic Composites
}

Arthur Babeau, Sébastien Comas-Cardona, Christophe Binetruy, Gilles

Orange

\section{To cite this version:}

Arthur Babeau, Sébastien Comas-Cardona, Christophe Binetruy, Gilles Orange. Modeling of Heat Transfer and Unsaturated Flow in Woven Fiber Reinforcements during Direct Injection-Pultrusion Process of Thermoplastic Composites. Composites Part A: Applied Science and Manufacturing, 2015, 77, pp.310-318. 10.1016/j.compositesa.2015.04.017 . hal-01150735

\section{HAL Id: hal-01150735 https://hal.science/hal-01150735}

Submitted on 11 May 2015

HAL is a multi-disciplinary open access archive for the deposit and dissemination of scientific research documents, whether they are published or not. The documents may come from teaching and research institutions in France or abroad, or from public or private research centers.
L'archive ouverte pluridisciplinaire HAL, est destinée au dépôt et à la diffusion de documents scientifiques de niveau recherche, publiés ou non, émanant des établissements d'enseignement et de recherche français ou étrangers, des laboratoires publics ou privés.

$$
\text { Copyright }
$$




\title{
Modeling of Heat Transfer and Unsaturated Flow in Woven Fiber Reinforcements during Direct Injection-Pultrusion Process of Thermoplastic Composites
}

\author{
Arthur Babeau $^{\mathrm{a}, *}$, Sébastien Comas-Cardona ${ }^{\mathrm{a}}$, Christophe Binetruy $^{\mathrm{a}}$, Gilles Orange $^{\mathrm{b}}$ \\ ${ }^{a}$ Research Institute GeM, UMR CNRS 6183, École Centrale de Nantes, 1 rue de la Noë, BP92101, 44321 \\ Nantes Cedex 3, France \\ ${ }^{b}$ Solvay, R8I Centre Lyon, 85 rue des Frères Perret, 69192 Saint-Fons, France
}

\begin{abstract}
This paper provides a methodology for the modeling of heat transfer and polymer flow during direct thermoplastic injection pultrusion process. Pultrusion was initially developed with thermosets which have low viscosity. But the impregnation becomes a critical point with thermoplastics which exhibit higher viscosity. There are very few reported works on direct thermoplastic impregnation with injection within the die. In addition, the rare studies have not adequately addressed the issue of unsaturated flow in woven fiber reinforcements. The solution proposed here, models the polymer flow through dual-scale porous media. A heat transfer model is coupled to a flow model enriched with a sink term. Specific changes of variables are made so as to model the steady state solution of unsaturation along a continuous process. The sink term, added to the continuity equation, represents the absorption rate of polymer by the bundles. Data were measured on a pultrusion line and micrographs confirmed the modeling strategy with an unsaturated flow approach. The flow modeling coupled to heat transfer of the thermoplastic pultrusion process aims at determining the saturation evolution through the die so as to manufacture pultruded profiles with the lowest residual porosity.
\end{abstract}

Keywords:

A: Thermoplastic resin, B: Porosity, E: Pultrusion, E: Resin flow

\footnotetext{
*Corresponding author

Email address: arthur.babeau@ec-nantes.fr (Arthur Babeau)
} 


\section{Introduction}

Pultrusion is a manufacturing technique that produces continuous profiles of composite materials. The process is used for the fabrication of profiles with constant cross-sections. Historically, thermoset resins have dominated the pultrusion industry because of their adhesion to reinforcements and efficient impregnation thanks to their low viscosity. But thermosets start to be replaced by thermoplastics. The latter are more difficult to process but offer improved impact strength and enhanced fracture toughness, allow post-thermoforming to create non-straight shapes and recycling [1]. Moreover pultrusion speeds up to $10 \mathrm{~m} / \mathrm{min}$ can be reached with thermoplastics [2]. This is why, for instance, automotive industry might be interested in this technology. During injection-pultrusion, continuous fibers impregnated with a liquid polymer are pulled through a die to form composites with a constant crosssection. Even though the impregnation step was not challenging with thermosets because of their low viscosity, it becomes a critical issue with melted thermoplastics due to their higher viscosity. The impregnation has a strong impact on the quality of pultruded products. A good understanding of this step is needed to limit the void formation. Once the impregnation step is achieved, the temperature control will also have an important impact on the final profile quality and can induced for instance residual stresses or shape distortions [3].

Most of the past efforts have been directed towards modeling of thermosets pultrusion. Price [4] and Han et al. [5] first developed mathematical models for simulating the thermoset pultrusion process. At that time, the goal was to model the temperature profile and the degree of cure within the composite profile. Although the cross-linking reaction does not concern non-reactive thermoplastic pultrusion, the heat transfer phenomenon remains. But other difficulties appear with thermoplastic matrices such as non-Newtonian flow behavior, matrix melting, solidification and crystallization. The first authors who have shown an interest in thermoplastic pultrusion modeling are Lee and Springer [6], Larock et al. [7] and Aström and Pipes [8]. Nevertheless, Lee et al. [9] and Aström and Pipes [10] were the first to develop a model coupling heat transfer, flow and pulling resistance of the thermoplastic process. The first flow modeling was presented by Batch and Macosko [11] who investigated 
the pressure rise in addition of the temperature distribution in the tapered region of the die with a thermoset polymer. Then Aström and Pipes [8] have proposed a one-dimensional model with an analytical solution using the Kozeny-Carman permeability expression coupled to a heat transfer model. Later, only focusing on the flow modeling, Raper et al. [12] have developed a two-dimensional model with an analytical transverse expression of the permeability of the tows (Gebart [13]). And even three-dimensional models have been developed recently to simulate the resin flow [14]. Moreover thermoplastic pultrusion with prepreg products such as commingled yarns [15] or powder-impregnated bundles [16, 17] have already been studied.

All these approaches model the polymer flow at a macroscopic scale without considering any microscopic effect. These models have not adequately addressed the issue of unsaturated flow in woven fibers during pultrusion process. The macroscale corresponds to the channels between the fiber bundles and the microscale to the channels between the fibers themselves. The purpose of this study is to show the importance of the microscale on the polymer flow and especially the impact on the residual porosity in the pultruded profile. The next part of this paper describes the materials used and the instrumented pultrusion line. Then a heat transfer model is presented and implemented thanks to temperature measurements done on the pultrusion line. In the fourth section, micrographs of pultruded profiles are shown and give indications of the impregnation phenomena occurring during the process. Then the dual-scale flow approach chosen for the flow modeling is explained and applied to the studied process. The sink term model applied here comes from the literature and is used to validate the modeling strategy. Finally results are presented and discussed. Such models help to better understand the thermoplastic pultrusion process, to optimize the process parameters: pulling speed, pressure within the die, permeability of the tapes, die geometries, etc. The final goal is to manufacture pultruded profiles with the lowest residual porosity. 


\section{Experimental work}

\subsection{Material}

The experimental tests were performed with multi-axial $\left(0^{\circ}, 90^{\circ}\right)$ plain weave glass fiber tapes (woven ribbons) with an areal weight of $800 \mathrm{~g} / \mathrm{m}^{2}$ and 50 or $100 \mathrm{~mm}$ in width. These woven ribbons will be called tapes in the following. The matrix was a high fluidity PA66 supplied by Solvay. It has a viscosity around 15 Pa.s at $280^{\circ} \mathrm{C}$. Compared to usual PA66 whose viscosity ranges from 200 to $300 \mathrm{~Pa}$.s, the high fluidity allows direct injection pultrusion to be carried out.

\subsection{Processing technology}

A schematic view of the pultrusion line used during the study is shown in figure 1. Dry tapes are pulled from several creels with a pulling mechanism. They are gathered before entering into a preheating system. The preheating is necessary to enhance the impregnation and to avoid too high temperature differences between fiber reinforcements and polymer. Then the tapes enter the heated die where the molten polymer is injected. The impregnation step takes place in the tapered portion of the heated die. There, the fiber/polymer system is compressed until the final profile geometry is reached (consolidation). The conformation happens at the exit of the die in the straight portion. It is where the exact geometry of the profile cross-section is formed. The cooling die at the end is necessary for thermoplastic pultrusion. In this region, the fiber/polymer system is solidified and the profile that emerges from the die is crystallized.

The pultrusion line was used to produce samples with rectangular cross-section (flat profiles figure 2, with a thickness of $3.2 \mathrm{~mm}$ and 5 plies or a thickness of $4 \mathrm{~mm}$ and 7 plies) and omega cross-section (figure 3, with a thickness of $4 \mathrm{~mm}$ and 7 plies). The targeted fiber volume fraction was between 45 and $55 \%$.

\subsection{Instrumentation}

The heated die was instrumented with thermocouples on several locations of the mold surface. The pulling force was monitored during the process but it was not possible to record 
it. In order to acquire continuous data of temperature, thermocouples were attached to the tapes to monitor the temperature along the overall pultrusion line.

\subsection{Void content observations}

For cross-sections analysis samples were cut out from pultruded profiles and prepared in an acrylic resin and polished up to 4000 grit $\mathrm{SiC}$ paper. Observations were performed with a Nikon Eclipse LV150 optical microscope and with a Nikon DS-Fi1 camera.

\section{Heat transfer modeling}

In this section the early work by Aström and Pipes [10] is applied to model the heat transfer along the pultrusion line. Temperature measurements were done on the pultrusion line for identification of heat coefficients. The heat transfer model will be coupled with the flow model within the heated die so it is necessary to have an accurate prediction of the temperature distribution within the tapes.

\subsection{D model}

Aström and Pipes [10] proposed a model with a one-dimensional transient heat transfer equation. They considered the pultrusion process of thermoplastic matrix composites reinforced by unidirectional fibers. In their case, prepreg tows enter into the die so they supposed an intimate contact between matrix and fibers was initially assured.

In [10, 2D geometry was considered for the die as shown in figure 4 . The height of the die was supposed small compared to the width so the heat transfer in the $y$ direction could be neglected. Moreover the height of the die was also small compared to its length so they considered the fibers nearly parallel to the $x$ axis and the composite was treated as a transversely isotropic material. The major assumptions of the heat transfer analysis were that $x$-axis conduction and polymer flow were negligible and that the fiber/polymer system could be considered as a homogeneous material. Moreover it was also assumed that the temperature was independent of the pressure and the viscous dissipation was negligible. Focusing on the heated die Aström and Pipes [10] simplified the model a bit further and also neglected sources arising from the melting and crystallization. 
The startup of the process is a transient state when the heaters have just been turned on. But after a time long enough the composite travels through the die at a constant speed $U$ and the process parameters remain constant (such as the temperature of the die walls) and the process is at steady state. Aström and Pipes studied the process without considering the transient state, they assumed the process at steady state. The relation between the time and the $x$ coordinate is given by $x=U t$. A complete heat transfer equation is derived in Baran et al. [18] considering a transient approach. Therefore the heat transfer equation may be written with spatial dependency $T(x, z)$ :

$$
\rho c U \frac{\partial T(x, z)}{\partial x}=\frac{\partial}{\partial z}\left(k \frac{\partial T(x, z)}{\partial z}\right)
$$

where $T$ is the temperature, $\rho$ and $c$ the lumped density and specific heat for the composite material respectively, $k$ the lumped thermal conductivity in $z$ direction. $x$ and $z$ are respectively the coordinates parallel and perpendicular to the pulling direction (figure 4) and $U$ the constant speed along the $x$-axis at which the composite is pulled.

They treated the composite as an infinite slab of finite height $W$ with either prescribed temperature or prescribed heat flux at the surfaces, $z= \pm W / 2$. Only half the slab was treated $(0 \leq z \leq W / 2)$ since the temperature profile was assumed symmetric with respect to the plane $z=0$.

The boundary conditions within the die were (see figure 12):

$$
\begin{array}{ll}
T(x, W / 2)=T_{\text {die }} & x \geq 0 \\
\frac{\partial T(x, 0)}{\partial z}=0 & x \geq 0 \\
T(0, z)=T_{0} & 0 \leq z \leq W / 2
\end{array}
$$

where $T_{0}$ is the composite temperature at the entrance of the die and $T_{\text {die }}$ the temperature of the die wall.

The general solution within the die may be written using Fourier series:

$$
T(x, z)=T_{\text {die }}+\frac{4}{W}\left(T_{0}-T_{\text {die }}\right) \sum_{n=0}^{\infty}\left[\frac{(-1)^{n}}{\lambda_{n}} \exp \left(-\lambda_{n}^{2} \frac{\frac{k}{\rho c} x}{U}\right) \cos \left(\lambda_{n} z\right)\right]
$$


where

$$
\lambda_{n}=\frac{(2 n+1) \pi}{W} \quad n=0,1,2 \ldots
$$

An other Fourier series solution was given by the author when the composite is exposed to the air before and after the die.

Their model assumed that a fibrous medium impregnated with polymer forms a macroscopically homogeneous material system for heat transfer analysis. It means that lumped density, specific heat and thermal conductivity for the composite were used. Their values depend on the matrix and fibers properties.

\subsection{Temperature measurements}

In this study four thermocouples were inserted within the heated die to record information at the surface between the fiber/polymer system and the die. In addition several thermocouples were used to monitor the temperature distribution along the pultrusion line from the preheater entry to the exit of the cooled die. To do that the thermocouples were attached to the tapes at several positions through the thickness. One of the thermocouple measurement is shown in figure 5. The temperature was recorded with profile thickness of $3.2 \mathrm{~mm}$ (5 plies) and the thermocouple was inserted between two tapes as shown in figure 6. The sketch in figure 5 indicates the position of the different pultrusion line elements.

\subsection{Analytical and numerical models}

To apply the analytical model presented in section 3.1, all the natural convection coefficients have to be determined. This has been solved through an inverse method with the temperature measurements. The different coefficients were determined in each zone: within the preheater, between preheater and heated die, between heated and cooled dies, and after the cooled die. With such a method, it is necessary for each testing campaign to insert a thermocouple along the pultrusion line since the coefficients might change depending on external parameters.

For the modeling, only dry tapes have been considered for the profile before the heated die (within the preheating system and in the air). Then in the heated die, lumped properties 
have been calculated with fiber volume fraction evolving from $36 \%$ to $55 \%$. Then after the heated die lumped properties were calculated considering a constant fiber volume fraction of $55 \%$. The rule of mixture has been used to obtain the homogenized density, and the inverse rule of mixture has been used for the specific heat and the thermal conductivity through the thickness (see Thomas [19]).

Then a numerical model was also implemented into Comsol Multiphysics, a finite element (FE) numerical software. The goal is to compare 2D analytical results with FE results to validate the analytical model. Figure 7 compares predictions of the analytical model presented in section 3.1 and the numerical model. It shows the temperature evolution along the pultrusion line at two points of the profile thickness: the surface and the center. A good match is obtained except for the temperature evolution in the cooled die. It can be explained by the high temperature gradient seen by the profile in this area. The mathematical model by Aström and Pipes [10] is not valid anymore if the temperature in the profile is not homogeneous through the thickness at the beginning of a new boundary condition domain (for instance between the die exit and the air).

The comparison between both models and the temperature measurement is shown in figure 8. The measurements are consistent with the simulations except at the entry and the exit of the preheater. The model assumes that the preheater temperature is uniformly constant, which might not be the case in reality. But the most important conclusion is that the heat transfer model is correct within the heated die. For the flow model, the studied domain will be limited to the heated die. The main interest in the analytical approach for the heat transfer is the possible simplification of the calculations for the coupling with the flow model. Nevertheless, in next sections, the heat transfer is solved numerically since the coupling is not too computationally expensive.

\section{Micrographic observations}

Several samples were produced with different process parameters combinations. At the end of the pultrusion line after the cooling, samples were cut out from profiles and polished to analyze cross-sections with an optical microscope (see section 2.4). 
Several micrographs are presented in figure 9. They were produced at the same pulling speed of $0.7 \mathrm{~m} / \mathrm{min}$, with 7 plies of glass fiber tape and with an die exit nominal thickness of $4 \mathrm{~mm}$. But the final thicknesses are different between those three samples. It can be explained by a difference of temperature at the exit of the heated die. Depending on this process parameter, the swelling of the fiber/polymer system at the exit of the die can differ because of different solidification states. Micrographs in figure 9 show diverse degrees of saturation, by saturation it is meant impregnation of the fiber bundles. Saturation degrees change between these samples because of the die temperature variations. The saturation is equal to 0 when the bundle is not impregnated (no polymer inside) and equal to 1 when it is fully impregnated. As shown in figure 10 the inter-tow volumes, which are the channels between the fiber bundles, seem to be completely impregnated by the matrix (matrix appears white on the micrographs). Whereas the intra-tow volumes which are the channels between the fibers within the bundles show different degrees of saturation (porosities appear in black).

The main observation is that during the impregnation of the woven fiber reinforcement, a dual-scale flow takes place. The polymer seems to have no difficulty to flow within the inter-tow volumes whereas it takes more time to impregnate the intra-tow volumes. As it will be seen in the next section, it can be assumed that at the heated die entry the composite is already macroscopically impregnated but bundles are unsaturated. This assumption means that the matrix fills the inter-tow volumes as soon as the tapes enter the die, whereas it takes some time to fill the bundles and depending on the process parameters it might be impossible to get a complete impregnation of the bundles.

These micrographs give process modeling indications of the occurring phenomena. The flow modeling approach might not be to determine a flow front location as the profile faces a rapid macroflow followed by a slower unsaturated microflow. Since the stack of fabrics is pulled and travels through the melt polymer, the notion of flow front is replaced by the notion of saturation. Therefore, the material (reinforcement and polymer) can be considered as an unsaturated porous medium that is consolidating along the die. Then the principal modeling aim is the prediction of the degree of saturation evolution along the die. 


\section{Unsaturated flow modeling}

During pultrusion with direct thermoplastic injection within the die, the polymer movement will be modeled as a flow within dual-scale porous media. As shown above, within the heated die, the fiber bundles can be considered completely surrounded by the liquid polymer and unsaturated. Then as the fiber bundles go through the tapered portion, the cross-sectional area becomes smaller, the bundles begin to saturate and the excess polymer starts to flow backward.

\subsection{Dual-scale flow model}

In this study a double scale porosity model is used. A sink term is added to the mass conservation equation:

$$
\nabla \cdot u=-q(P, S)
$$

where $q$ is the sink term which represents the absorption of the polymer by the bundles, $P$ the macroscopic pressure and $S$ the bundles saturation (equals to 0 if not saturated, 1 if fully saturated). This approach was used by several authors such as Parnas and Phelan [20], Chan and Morgan [21], Pillai and Advani [22], Bréard et al. [23] or Gourichon et al. [24]. Park and Lee [25] also mentioned this approach in the review of the unsaturated flow in liquid composites.

At the macroscale, Darcy's law is applied to model the flow between the bundles. The macroscopic permeability is chosen considering the bundles as impermeable. The flow at the microscale is modeled within the sink term $q$. The two-scales domain is represented in figure 11

\subsection{Microscopic flow model}

The approach developed by Wang and Grove [26] was applied. The authors represent the woven reinforcements microstructure with a 2D unit cell and studied the evolution of the saturation as a function of time. The results of numerical simulations show a relationship between the saturation kinetics, the macroscopic pressure and the saturation:

$$
\frac{d S}{d t}=\frac{a P}{\beta \eta}\left(e^{\left(b(1-S)^{c}\right.}-1\right)
$$


where $a, b, c$ and $\beta$ are constant curve fitting parameters determined for a unit cell geometry, $\eta$ the matrix viscosity, $P$ the surrounding local macroscale matrix pressure.

The sink term which represents the rate of the polymer volumetric ratio which flows from inter-tow volumes into intra-tow volumes can be expressed as a function of the saturation kinetics:

$$
q(P, S)=\epsilon_{\text {micro }}\left(1-\epsilon_{\text {macro }}\right) \frac{d S}{d t}
$$

where $\epsilon_{\text {micro }}$ and $\epsilon_{\text {macro }}$ are respectively the porosity within fiber bundles and within the macroscopic gap.

\subsection{Governing equations and coupling applied to thermoplastic pultrusion}

Thanks to the volume averaging method by [27] and [28] and the change of variables between time $t$ and $x$-coordinate $(x=U t)$, the flow model equations can be derived as follow. The mass conservation in equation 4 becomes:

$$
\nabla \cdot\langle u\rangle=-q
$$

where $\langle u\rangle$ is the volume averaged polymer velocity in the inter-tow volumes. The sink term expression in equation 6 becomes:

$$
q=\epsilon_{\text {micro }}\left(1-\epsilon_{\text {macro }}\right) U \frac{d S}{d x}
$$

The sink term model relationship changes into:

$$
\frac{d S}{d x}=\frac{1}{U} \frac{a P}{\beta \eta}\left(e^{\left(b(1-S)^{c}\right.}-1\right)
$$

where the values for $a, b, c$ and $\beta$ are given by [26] $(a=0.1462, b=5.613, c=0.9533$ and $\beta=2 \cdot 10^{6}$ ). These constant coefficients depend on the fixed unit cell chosen and do not vary with the fiber reinforcement compaction. The polymer flow at the macroscopic scale during pultrusion can be modeled as Darcy's law in a moving frame with a constant speed. The equation was derived by [27]:

$$
\langle u\rangle-\epsilon_{\text {macro }} U=-\frac{K}{\eta} \nabla P
$$


where $K$ is the macroscopic permeability tensor considering bundles as impermeable. In this study an isotropic permeability $K$ was used. Because of the tapered region in the die, the permeability is $x$-coordinate dependent, since the fiber volume fraction increases along the die. Results obtained by Comas-Cardona et al. [29] with glass fiber plain weave were used. An extrapolation was made to obtain permeability values for low fiber volume fractions (under $45 \%$ ). The permeability values used in this study had been: $10^{-7} \mathrm{~m}^{2}$ at the die entry (fiber volume fraction of $36 \%$ ) and $10^{-10} \mathrm{~m}^{2}$ at the exit (fiber volume fraction of $55 \%$ ). And the logarithm of the permeability is changing linearly from -7 to -10 in between.

The boundary conditions applied to the domain are represented in figure 12. So, as already explained, the tows saturation is supposed equal to 0 at the die entry. Then the pressure is supposed to be null at the entry and the exit, and polymer velocity normal to the die walls is equal to 0 (no in or out flux through the die walls).

\subsection{Heat transfer coupling}

The flow model is coupled to the heat transfer model presented in section 3 . The polymer viscosity is expressed as a function of the temperature. An exponential model was used:

$$
\eta(T)=a \exp \left(-\frac{T}{b}\right)
$$

where $\eta$ is the polymer viscosity, $T$ the temperature of the fiber/polymer system calculated by the heat transfer model, $a$ and $b$ constant coefficients $\left(a=3.10^{6}\right.$ Pa.s and $\left.b=45.45 \mathrm{~K}\right)$. These coefficients were chosen according to rheologic properties given by Solvay. They lead to a viscosity of 30 Pa.s at $250^{\circ} \mathrm{C}, 15$ Pa.s at $280^{\circ} \mathrm{C}$ and 10 Pa.s at $300^{\circ} \mathrm{C}$. The goal is to check the temperature dependent viscosity influence on the impregnation step.

Equations (7- 11) are coupled and solved with Comsol Multiphysics software through finite element method.

\section{Results and discussion}

The aim is to predict the saturation level (residual porosity level) of the fiber bundles at the exit of the heated die. The influences of processing parameters are analyzed and results 
are shown in figures 13 to 17 for sensitivity of pulling speed, polymer viscosity, die geometry and temperature distribution. For the sensibility analysis, only one parameter is modified while the others remain unchanged. All the figures 13 to 17 show the evolution of pressure and saturation at the profile center along the die.

\subsection{Pulling speed}

The figure 13 shows the pressure and saturation distribution along the heated die for three different pulling speeds: $0.1,0.5$ and $1 \mathrm{~m} / \mathrm{min}$. These results were obtained with a polymer viscosity of $15 \mathrm{~Pa}$.s and a fixed die geometry (same length, same taper angle). As it was intuitively expected, a fast pulling speed induces a higher pressure. But the saturation distributions are exactly the same, the three curves are superimposed on each other. This result is counterintuitive. With a higher polymer pressure, a better tow impregnation would be expected. But an other important parameter is the time of residency within the die. If the speed increases, the time of residency decreases so it influences the impregnation. In equation 9 the saturation kinetics is inversely proportional to the pulling speed. The conclusion of these simulations is that when the pulling speed increases, there is a balance between the increase of pressure and the decrease of the residency time, thus it does not influence the saturation evolution.

However in reality the results might be different. An increase in the pulling speed will induce an increase in the pulling force. Thus the fiber tows will be squeezed, individual fibers will be closer to each other in the fiber bundle and that will change the unit cell used in the model. But in the approach developed here, this unit cell is considered non-deformable.

\subsection{Polymer viscosity}

The results for three viscosity values: 1, 10 and 50 Pa.s are presented in figure 14. These simulations were run with a pulling speed of $0.5 \mathrm{~m} / \mathrm{min}$ and the same die geometry. The pressure graph shows that a polymer viscosity increase induces more pressure within the die. But again it does not seem to have any influence on the saturation distribution. One explanation is that when the viscosity increases, the flow through the bundles is hindered. 
Again, equation 9 shows that the saturation kinetics is inversely proportional to the polymer viscosity. So when the polymer viscosity increases, there is a balance between the pressure increase and the resistance to flow inside the bundles.

One interesting point is also that with a high polymer viscosity (around 50 Pa.s), the pressure within the die reaches almost $5 \mathrm{MPa}$. Such a pressure might be an issue for the process because it would induce a pulling force increase and the tapes would break. Also the die should be designed and highly strengthened so as to withstand that pressure. These simulations reveal the importance of working with a low viscosity polymer for thermoplastic pultrusion such as the PA66 used in this work $\left(15\right.$ Pa.s at $\left.280^{\circ} \mathrm{C}\right)$.

\subsection{Die geometry}

Two die geometry parameters were studied: the taper angle and the taper length. These results were obtained with a pulling speed of $0.5 \mathrm{~m} / \mathrm{min}$ and a polymer viscosity of 15 Pa.s.

The figure 15 shows that a taper angle increase induces a pressure and a saturation increase. So the taper angle is a critical process parameter. However as already mentioned in the previous section, a too high pressure in the die might damage the tapes. So compromise has to be found for the taper angle to get a good saturation without too much pressure.

A similar result is shown in figure 16 for the taper length. The vertical lines on the figures represent the end of the taper length for each value. As expected, the longer the taper, the higher the polymer pressure. And it has a direct influence on the saturation. Moreover the time of residency increases also when the taper is longer, so the polymer has more time to flow within the tows.

The conclusion of these results is that the die geometry is a critical process parameter. Depending on the targeted pulling speed and the polymer viscosity, the right combination of taper angle and length has to be chosen to get a pultruded profile with limited porosity.

\subsection{Temperature distribution influence on saturation}

The previous results were obtained without heat transfer coupling. The polymer viscosity was supposed constant in the domain. In this section equation 11 is introduced in the model 
and temperature will not be assumed homogeneous within the die. The die wall temperatures are set to $280^{\circ} \mathrm{C}$ in the first straight portion and in the tapered portion. Then three different temperatures are applied in the last straight shape portion before the exit: $250{ }^{\circ} \mathrm{C}, 270^{\circ} \mathrm{C}$ and $290{ }^{\circ} \mathrm{C}$.

The figure 17 shows the pressure and saturation distribution along the heated die for the three different temperatures. There is a slight difference in the pressure distributions. With the highest temperature the polymer viscosity (given by equation 11) is lower, so the pressure is lower. But for the same reasons as given in section 6.2 (balance between pressure and resistance to flow inside the tows), the influence on the saturation evolution remains limited. It can be noticed that the degree of saturation at the exit is slightly higher with a higher temperature in the last die portion.

However, in practice, the goal will be to decrease the profile temperature before the exit of the die to avoid any swelling of the profile. But at the same time decreasing the temperature hinders the saturation evolution. So an accurate control of the temperature is mandatory to get a high degree of saturation at the end of the heated die tapered portion. Baran et al. [30] have shown the importance of a good profile temperature control otherwise residual stresses and cross-section distortions can be induced.

\section{Conclusion}

Knowing that the temperature might be an important parameter to get a good saturation in pultruded profile, the first step of the study was the heat transfer modeling. Convection coefficients were identified by an inverse method that relies on temperature measurement and an analytical model. Then micrographs of pultruded profiles were observed, and it has been noticed that the polymer impregnated easily the macroscopic channels. So the main hypothesis for the flow model was to assume that the inter-tow volumes are impregnated as soon as the fiber reinforcements enter the die. The goal of the flow model was to capture the saturation of the fiber tows along the die. An unsaturated flow approach with a sink term was implemented as well as a coupling with the heat transfer with a temperature dependent viscosity. The originality of this work also stands into the changes of variables to simulate 
the steady state of the continuous process which exhibits consolidation of an unsaturated double scale medium. The simulation results show that the process parameter that has the main influence on the profile degree of saturation is the die geometry, such as the taper angle and the taper length. The temperature of the die exit has only a limited influence and the pulling speed or the polymer viscosity does not change the final degree of saturation in the implemented model.

During pultrusion process, the temperature distribution within the die can be more complex and in the future it might be necessary to model the whole die and the heated coils. Indeed, as viscosity depends on the temperature, using a temperature gradient within the die instead of a uniform temperature might enhance the impregnation. Besides a more precise identification of the profile void content might be necessary. This is important for a good validation of the flow model. In this paper only qualitative porosity identification was done, but a more precise image analysis identification will be carried out. Moreover the complexity of the sink term model will be increased to capture more accurately the fiber tows saturation

phenomenon. For instance it should depend on the fiber reinforcements compaction. Using the work by [24], a new approach for the sink term in the mass balance could be proposed. It would take into account the actual surface exchange between two porous media and the potential exchanges between them. In addition an increase of pressure within the polymer should induce a local compaction of the tows. This compaction should decrease the local tows permeability. In a next stage this phenomenon will be considered, thus changing the viscosity of the polymer could influence the final saturation degree contrarily to the results shown in section 6.2 .

\section{Acknowledgements}

The authors thank Solvay for financially supporting this project and providing the polymer for the process. All the testings (measurements and sampling) were done during the SILWET project with CETIM, AMGP, Solvay and École Centrale de Nantes. 


\section{References}

[1] S. G. Advani, E. M. Sozer (Eds.), Process Modeling in Composites Manufacturing, Marcel Dekker, 2003.

[2] L. Destouches, Pultrusion, Techniques de l'Ingénieur AM 3730 (2010).

[3] I. Baran, C. C. Tutum, M. W. Nielsen, J. H. Hattel, Process induced residual stresses and distortions in pultrusion, Composites Part B: Engineering 51 (2013) 148 - 161.

[4] H. L. Price, Curing and flow of thermosetting resins for composite material pultrusion, Ph.D. thesis, Old Dominion University, 1979.

[5] C. D. Han, D. S. Lee, H. B. Chin, Development of a mathematical model for the pultrusion process, Polymer Engineering and Science 26 (1986) 393-404.

[6] W. I. Lee, G. S. Springer, A model of the manufacturing process of thermoplastic matrix composites, Journal of Composite Materials 21 (1987) 1017-1055.

[7] J. A. Larock, H. T. Hahn, D. J. Evans, Pultrusion processes for thermoplastic composites, Journal of Thermoplastic Composite Materials 2 (1989) 216-229.

[8] B. T. Aström, R. B. Pipes, Modeling of a thermoplastic pultrusion process, in: 46th Annual Conference, Composites Institute, The Society of Plastics Industry, Inc., Washington, DC, 1991.

[9] W. I. Lee, G. S. Springer, F. N. Smith, Pultrusion of thermoplastics - a model, Journal of Composite Materials 25 (1991) 1632-1652.

[10] B. T. Aström, R. B. Pipes, A modeling approach to thermoplastic pultrusion. I: Formulation of models, Polymer Composites 14 (1993) 173-183.

[11] G. L. Batch, C. W. Macosko, A computer analysis of temperature and pressure distributions in a pultrusion die, in: 42nd Annual Conference, Composites Institute, The Society of Plastics Industry, Inc., Cincinati, OH, 1987.

[12] K. S. Raper, J. A. Roux, T. A. McCarty, J. G. Vaughan, Investigation of the pressure behavior in a pultrusion die for graphite/epoxy composites, Composites Part A: Applied Science and Manufacturing 30 (1999) 1123-1132.

[13] B. R. Gebart, Permeability of unidirectional reinforcements for RTM, Journal of Composite Materials 26 (1992) 1100-1133.

[14] A. L. Jeswani, J. A. Roux, Impact of fiber volume fraction and resin viscosity with die-detached tapered chamber in resin injection pultrusion, Journal of Manufacturing Science and Engineering 132 (2010) 021007 .

[15] D.-H. Kim, W. I. Lee, K. Friedrich, A model for a thermoplastic pultrusion process using commingled yarns, Composites Science and Technology 61 (2001) 1065-1077.

[16] G. Sala, D. Cutolo, The pultrusion of powder-impregnated thermoplastic composites, Composites Part 
A: Applied Science and Manufacturing 28 (1997) 637-646.

[17] A. H. Miller, N. Dodds, J. M. Hale, A. G. Gibson, High speed pultrusion of thermoplastic matrix composites, Composites Part A: Applied Science and Manufacturing 29 (1998) 773-782.

[18] I. Baran, J. Hattel, C. Tutum, Thermo-chemical modelling strategies for the pultrusion process, Applied Composite Materials 20 (2013) 1247-1263.

[19] M. Thomas, Propriétés thermiques de matériaux composites : caractérisation expérimentale et approche microstructurale, Ph.D. thesis, Université de Nantes, 2008.

[20] R. Parnas, F. Phelan, The effect of heterogeneous porous media on mold filling in resin transfer molding, Sampe quarterly (1991).

[21] A. W. Chan, R. J. Morgan, Tow impregnation during resin transfer molding of bi-directional nonwoven fabrics, Polymer Composites 14 (1993) 335-340.

[22] K. M. Pillai, S. G. Advani, A model for unsaturated flow in woven fiber preforms during mold filling in resin transfer molding, Journal of Composite Materials 32 (1998) 1753-1783.

[23] J. Bréard, Y. Henzel, F. Trochu, R. Gauvin, Analysis of dynamic flows through porous media. Part I: Comparison between saturated and unsaturated flows in fibrous reinforcements, Polymer Composites 24 (2003) 391-408.

[24] B. Gourichon, C. Binetruy, P. Krawczak, A new numerical procedure to predict dynamic void content in liquid composite molding, Composites Part A: Applied Science and Manufacturing 37 (2006) 19611969.

[25] C. H. Park, W. I. Lee, Modeling void formation and unsaturated flow in liquid composite molding processes: a survey and review, Journal of Reinforced Plastics and Composites 30 (2011) 957-977.

[26] Y. Wang, S. Grove, Modelling microscopic flow in woven fabric reinforcements and its application in dual-scale resin infusion modelling, Composites Part A: Applied Science and Manufacturing 39 (2008) $843-855$.

[27] C. L. Tucker III, R. B. Dessenberger, Governing equations for flow and heat transfer in stationary fiber beds, in: S. G. Advani (Ed.), Flow and Rheology in Polymer Composites Manufacturing, Elsevier Science Publishers, 1994, pp. 257-323.

[28] K. M. Pillai, Governing equations for unsaturated flow through woven fiber mats. part 1. Isothermal flows, Composites Part A: Applied Science and Manufacturing 33 (2002) 1007-1019.

[29] S. Comas-Cardona, C. Binetruy, P. Krawczak, Unidirectional compression of fibre reinforcements. part 2: A continuous permeability tensor measurement, Composites Science and Technology 67 (2007) 638 -645 .

[30] I. Baran, J. H. Hattel, R. Akkerman, Investigation of process induced warpage for pultrusion of a rectangular hollow profile, Composites. Part B : Engineering 68 (2015) 365 - 374. 


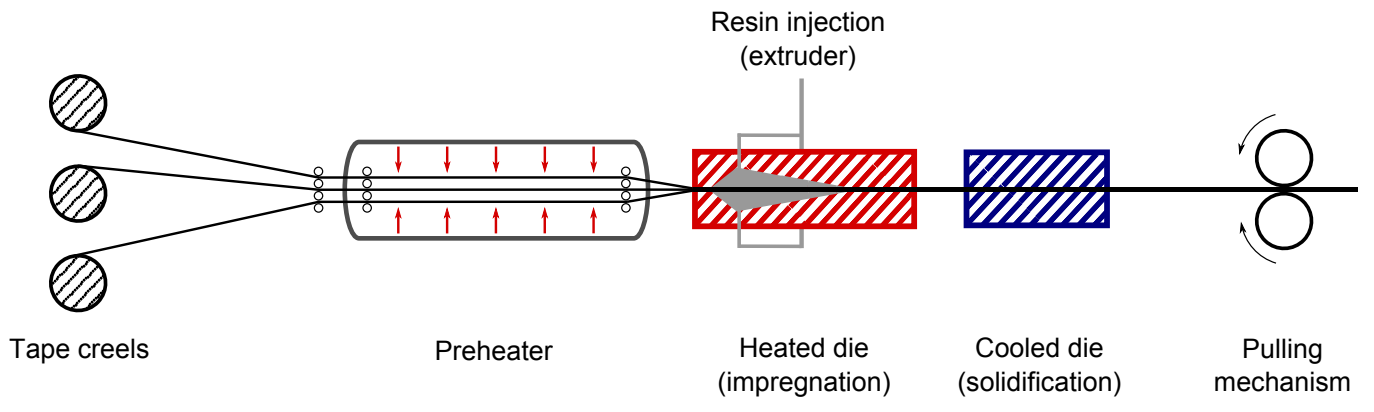

Figure 1: Schematic of direct injection pultrusion for thermoplastics

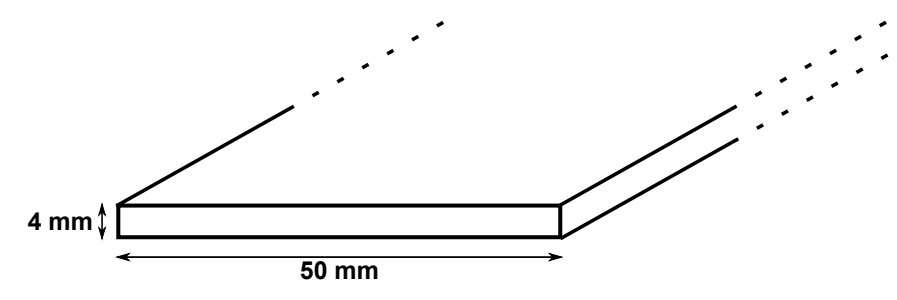

Figure 2: Flat profiles produced with the pultrusion line

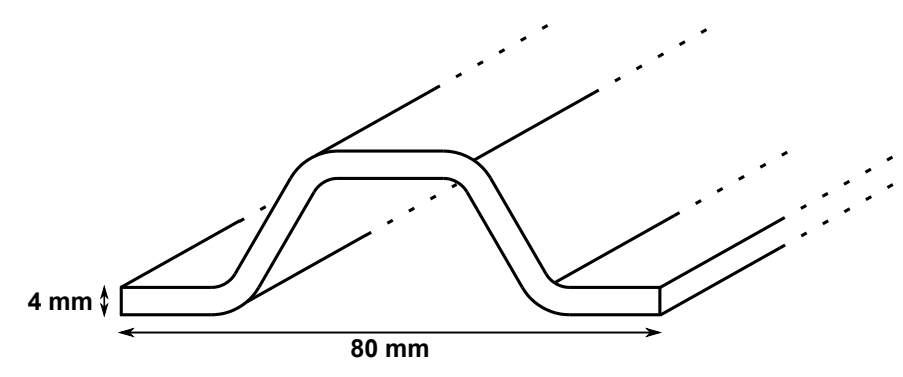

Figure 3: Omega profiles produced with the pultrusion line

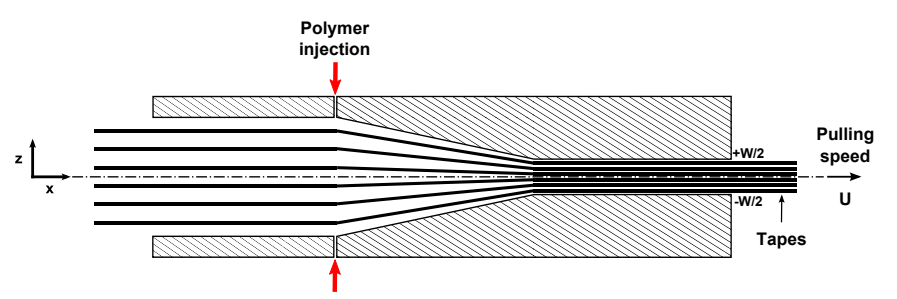

Figure 4: Geometry of the heated die used for the modeling 


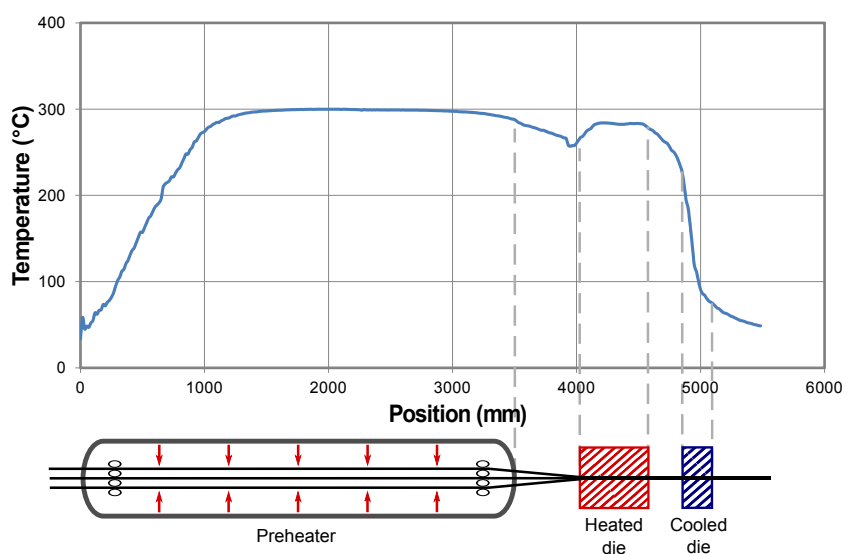

Figure 5: Temperature measured with a thermocouple along the pultrusion line $\left(U=1 \mathrm{~m} / \mathrm{min}, V_{f}=46.6 \%\right.$, $W=3.2 \mathrm{~mm}$, thermocouple position: $z=+W / 4$ )

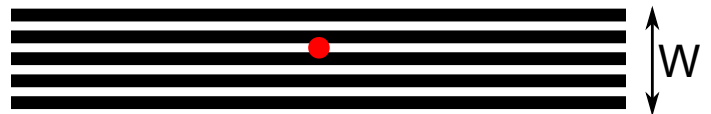

Figure 6: Thermocouple location in profile cross-section 


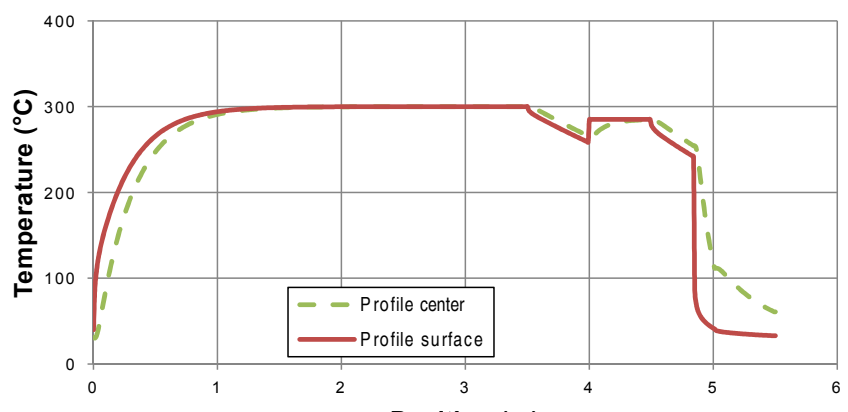

Position (m)

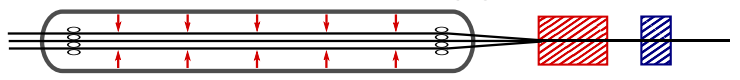

(a) Analytical model results

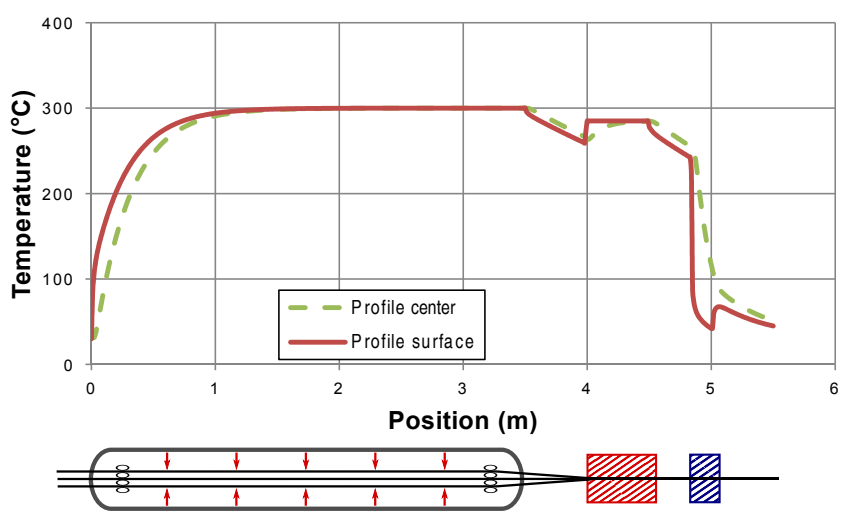

(b) Numerical model results

Figure 7: Analytical and numerical simulations

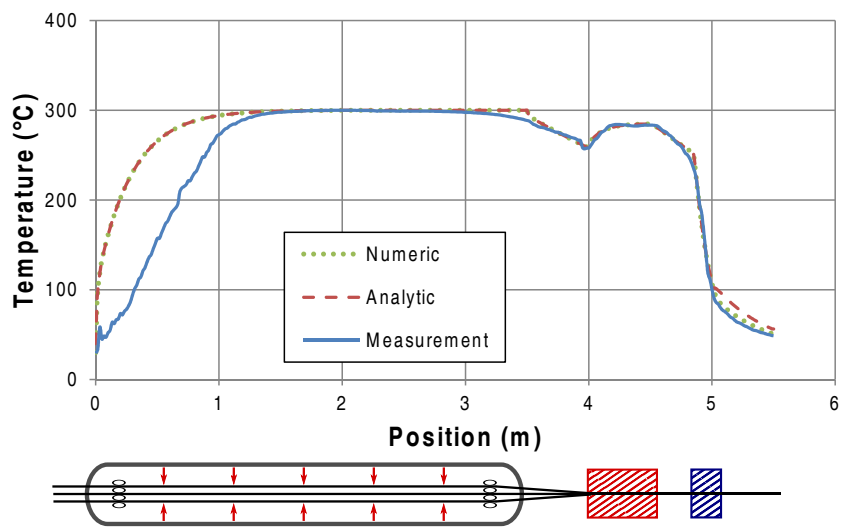

Figure 8: Comparison between analytical, numerical models and temperature measurements 

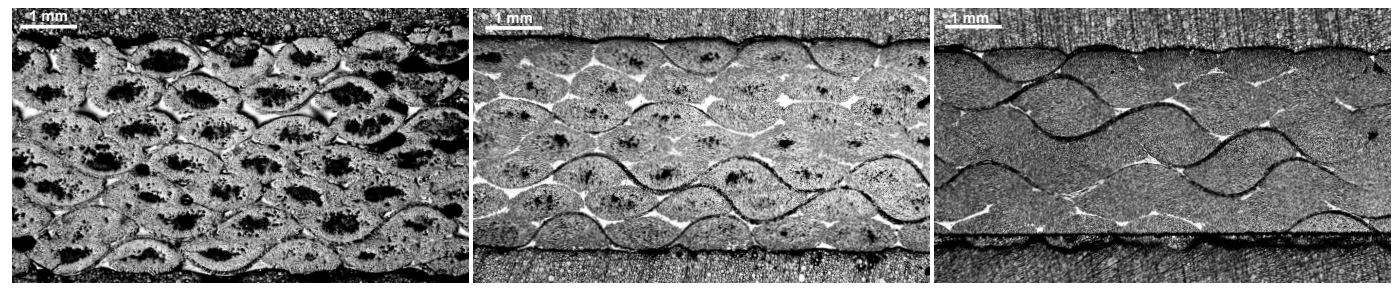

Figure 9: Micrographs of pultruded profile sections from left to right from the less saturated to the most saturated (profiles produced with 7 plies, $U=0.7 \mathrm{~m} / \mathrm{min}, W=4 \mathrm{~mm}$ but with different die exit temperatures)
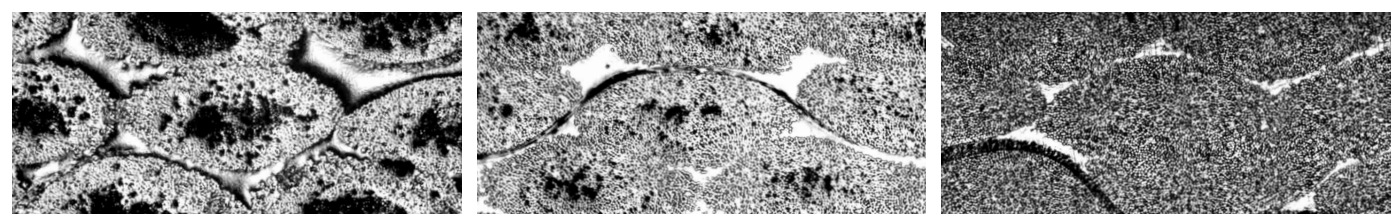

$1 \mathrm{~mm}$

Figure 10: Enlargements of the pultruded profile sections shown in figure 9

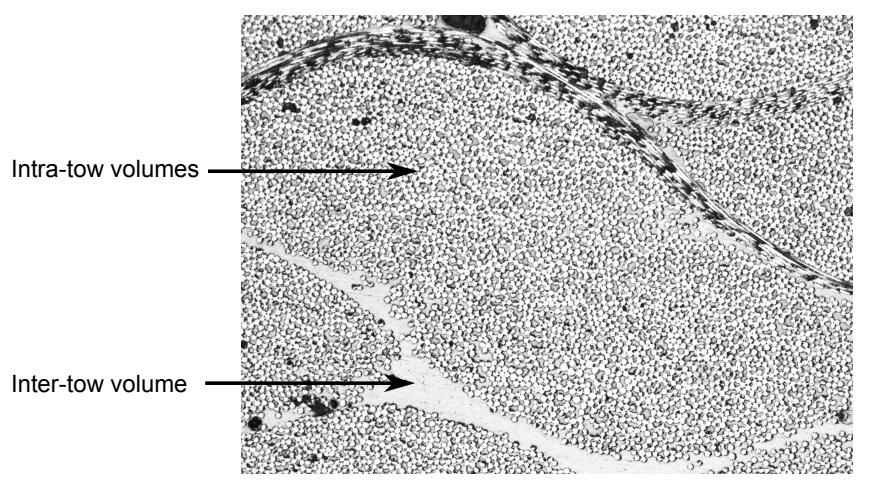

Figure 11: Micrograph representing the dual-scale domain

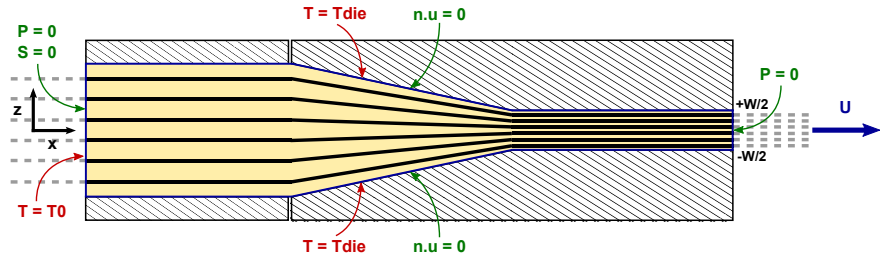

Figure 12: Boundary conditions applied to the heated die domain for the flow modeling 


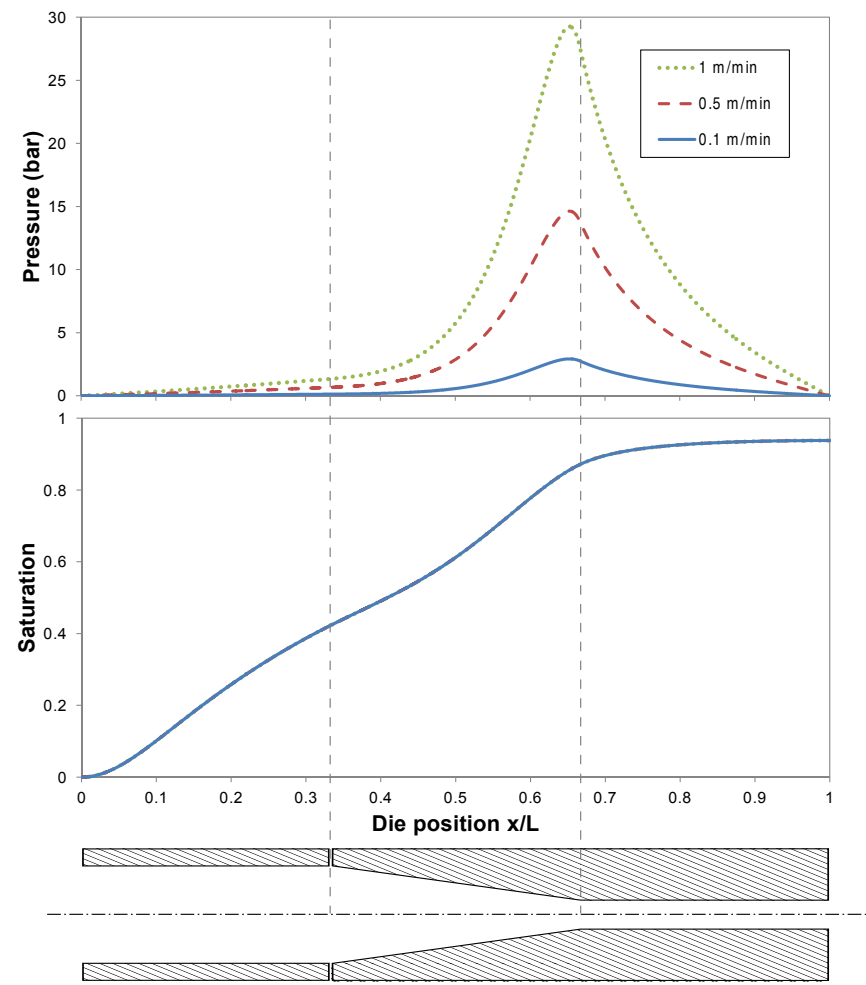

Figure 13: Pressure and saturation results at the profile center for several pulling speeds (polymer viscosity $=15$ Pa.s, die geometry fixed) 


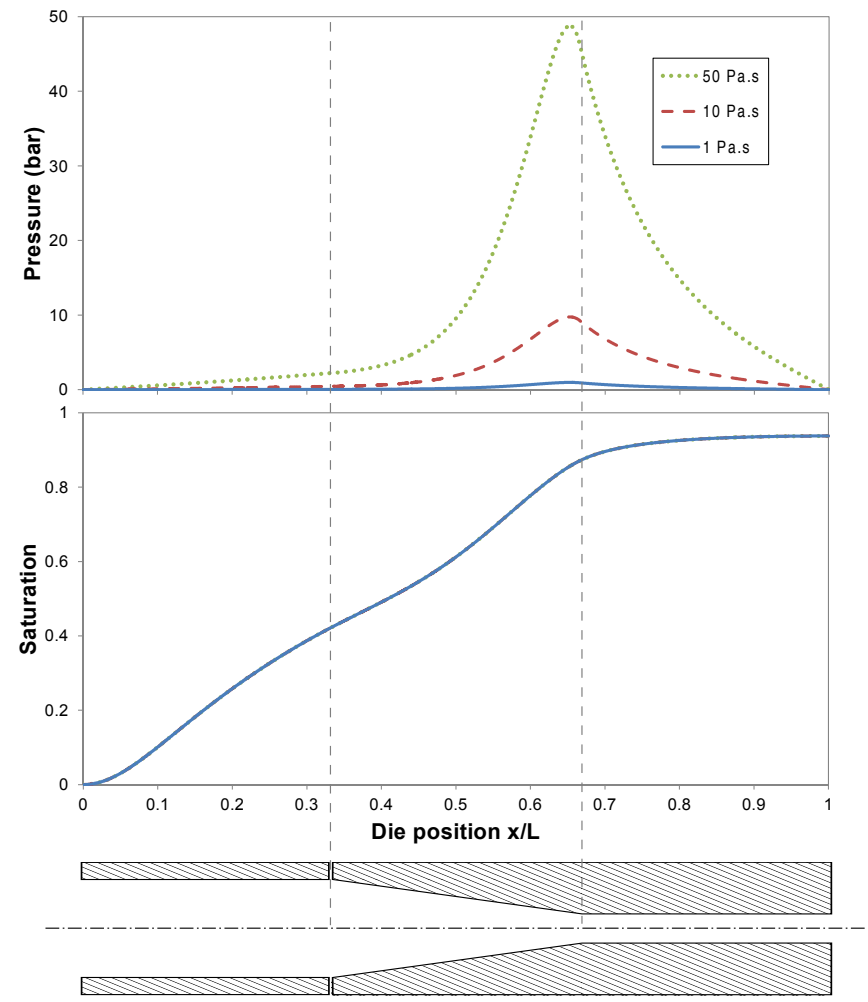

Figure 14: Pressure and saturation results at the profile center for several polymer viscosities (pulling speed $=0.5 \mathrm{~m} / \mathrm{min}$, die geometry fixed) 


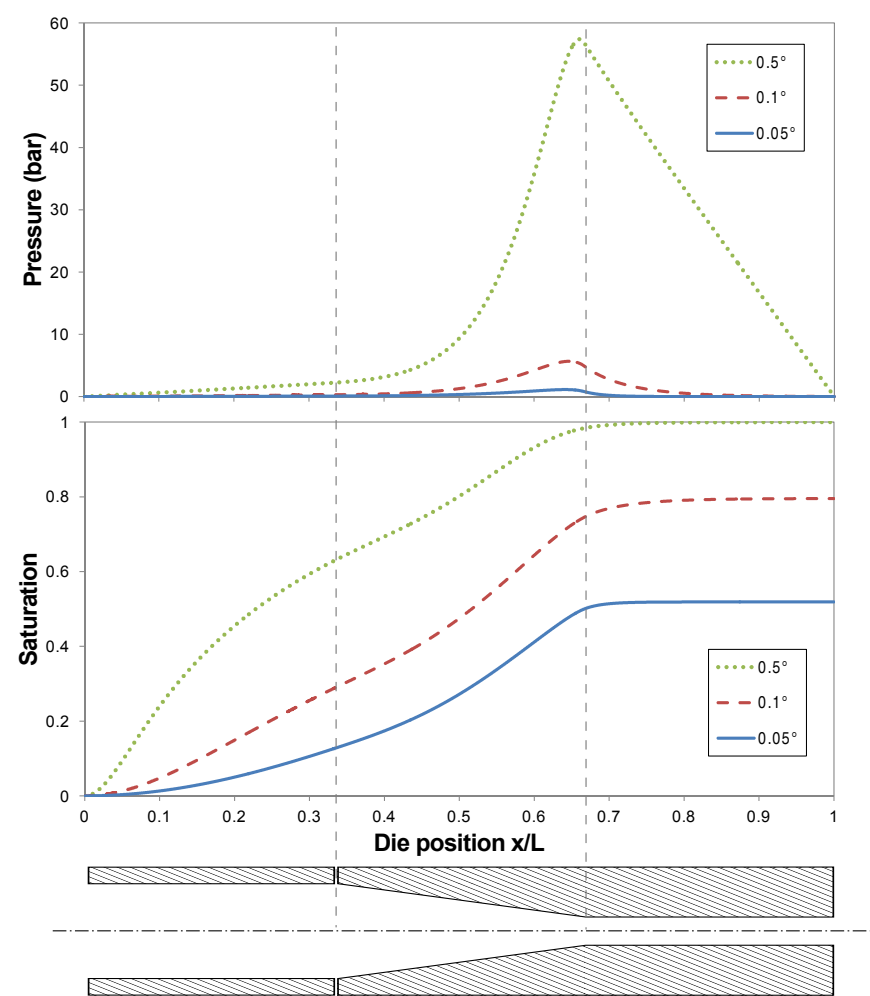

Figure 15: Pressure and saturation results at the profile center for several taper angles (pulling speed $=0.5$ $\mathrm{m} / \mathrm{min}$, polymer viscosity $=15$ Pa.s, taper length fixed) 


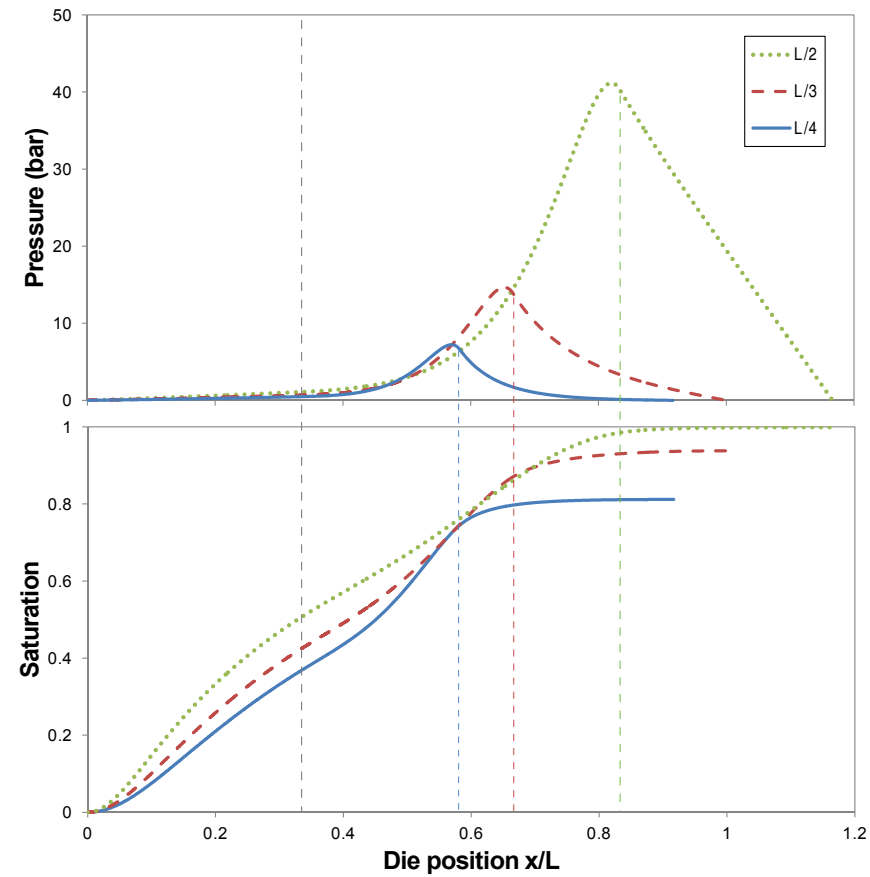

Figure 16: Pressure and saturation results at the profile center for several taper lengths (pulling speed $=$ $0.5 \mathrm{~m} / \mathrm{min}$, polymer viscosity $=15$ Pa.s, taper angle $=0.15^{\circ}$ ) 


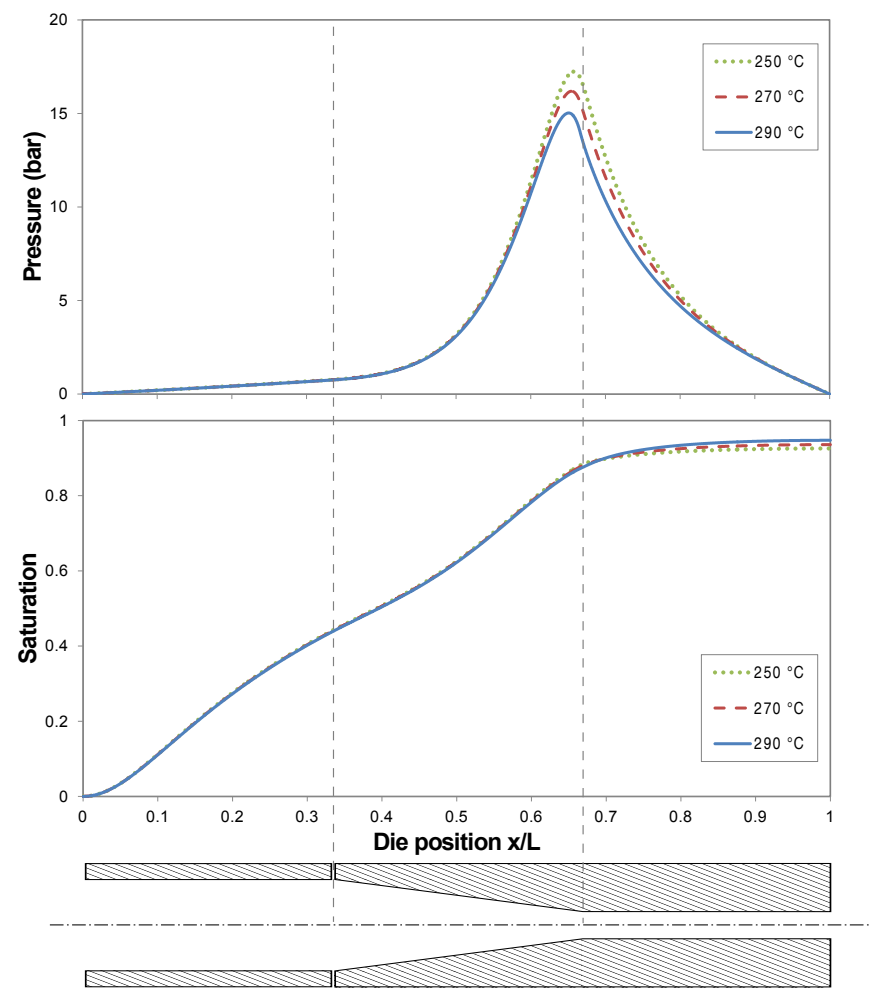

Figure 17: Pressure and saturation results at the profile center for several die exit temperatures (pulling speed $=0.5 \mathrm{~m} / \mathrm{min}$, same die geometry) 